Thorax (1946), 1, 100

\title{
PULMONARY TUBERCULOSIS IN AFRICAN NATIVE TROOPS
}

\author{
BY \\ NEVILLE C. OSWALD \\ From a Military Hospital, Middle East Forces
}

Several important papers have been written describing various aspects of pulmonary tuberculosis in negro races (Dumas, 1919; Borrel, 1920 ; Opie, 1924 and 1930 ; Report on South African Natives, 1932 ; Allen, 1932 ; Everett, 1933 ; Pinner and Kasper, 1932 ; Cummins, 1939 ; Israel and Payne, 1940). An acute course, with a high incidence of gross glandular enlargement and of tuberculous pneumonia, is well recognized as characteristic. This paper deals with 416 African coloured troops in whom pulmonary tuberculosis was diagnosed whilst they were on active service in the Mediterranean theatre, during a period of one year (1944-5). They comprised East Africans (Kenya, Uganda, Tanganyika, and Northern Rhodesia), West Africans (Nigeria), South Africans (Cape Coloured, a mixed race, mainly Dutch and Hottentot), and troops from the High Commissioned Territories (Basutoland, Bechuanaland, and Swaziland). The great majority had lived in tents in the deserts of Egypt, North Africa, and Palestine, being employed as pioneers, motor drivers, guards for static installations, medical orderlies, and gunners. A few saw active service in North Africa and Italy. The 416 cases were studied in the African Section of a Military Hospital in Egypt, where all Africans suffering from tuberculosis were collected prior to repatriation. The clinical features will be described, together with the post-mortem findings in 50 of the 51 patients who died in the hospital during the year.

\section{HISTORICAL}

Tuberculosis, which has probably existed in Egypt since Dynastic times (Elliott Smith, 1902), may have been introduced, as a result of trading, into a few of the coastal tribes of East Africa in the distant past. Apart from this, the negro races of Africa were probably free from tuberculosis until the end of the fifteenth century and remained so until infection was brought to them by Europeans.

Prior to the beginning of the sixteenth century there is no evidence of any significant penetration of East, South, or West Africa by European races. 
Following upon Vasco da Gama's discoveries in 1498, however, Portuguese settlements began to appear at scattered points down the west coast and along that part of the east coast now known as Mozambique. The Dutch formed a colony at the Cape in 1652, and by the end of the seventeenth century there were several flourishing European communities along the coast of Africa. At first, contact with the natives was limited, but as trading and missionary activities developed penetration of the interior of the Continent became more extensive. This process, augmented by the British and French, has continued ever since.

\section{Prevalence of Tuberculosis}

Despite these many sources of infection in the past, tuberculosis did not become an important disease amongst the natives until the middle of the nineteenth century. Lichtenstein (1803) found none amongst the Bantu in 1803-6. Livingstone (1857) stated that "tuberculosis did not exist in the interior"; Macvicar (1908) was of the same opinion in 1894. Cummins (1939) found none among the Dinka, in a remote part of the Southern Sudan in 1902. On the other hand, in the centres of civilization in South Africa, the disease had become established amongst the natives by about 1860 (Stewart, Girdwood, quoted in "Report on South African Natives," 1932). Gregory (quoted in the same Report) stated that, in 1895, "of all the diseases attacking the natives and Coloured" (of Cape Colony) "tuberculosis is by far the most important."

In recent years, tuberculin testing by the Mantoux method has shown that infection has become widespread. Wilcocks (1932), in Tanganyika, found 60-64 per cent of the adult males to have a positive skin reaction. Van den Branden, Fornara, and Staub (1926) found that 50 per cent of the adult population of Leopoldsville in the Belgian Congo were infected. Allen (1933) found that about 69 per cent of the adult males of Basutoland and the Matatiele area showed a positive reaction, and 88 per cent of the adult males in the coastal area of Butterworth, south-east of Basutoland. Dormer, Friedlander, and Wiles (1943) found $80-85$ per cent of positive reactors amongst the Bantu and the Coloured race in Natal.

It is evident that the natives in South Africa have now become widely infected with tuberculosis, and this applies particularly to those who have settled down in fixed communities in or near the large cities, or who have worked in the vast mining industries. In East and West Africa the infection is less widespread, whilst in the remoter parts of the Continent, especially amongst the nomadic tribes, tuberculosis continues to be a rare disease.

\section{Morbidity and MoRtality Rates}

These cannot possibly be estimated accurately in the Native Territories at the present time. The vastness of the African Continent presents insuperable diffi- 
culties to the handful of medical men working there. In British Africa statistics are compiled by the various Colonies and Dependencies, their mode of presentation being governed by local conditions.

(a) South Africa.-Dormer et al. (1943), combining the public health statistics for Cape Town, Johannesburg, Durban, and Port Elizabeth, estimate that the average tuberculosis mortality for the Bantu for the period 1933-42 was about 225 per 100,000 per annum, and for the Coloured, 385 per 100,000 per annum.

A committee of inquiry into "Tuberculosis in South African Natives, with special reference to the disease amongst the mine labourers of the Witwatersrand" (1932) found that the number of fresh cases of tuberculosis in the mine labourers varied between 6.62 and 7.53 per 1,000 per annum in the years 1926-9. Of these, about one-sixth were unfit to travel and died on the Rand, and of those who were repatriated, nearly a half were dead within a year and 60 per cent were dead within two years. This, then, is the magnitude of the tuberculosis problem in the gold-mining industry, which employs roughly 200,000 natives, drawn from all over Southern Africa.

During the past hundred years, tuberculosis has steadily spread among the native races of South Africa, and has now become a formidable medical problem. Mortality rates are still rising (Dormer et al.), and if the peak is not reached soon, the disease may seriously affect the industrial life of the country, dependent as it is upon native labour.

(b) East Africa.-In the "Annual Report of the Medical Department, Tanganyika" (1940), it is stated that "tuberculosis continues to show a steady annual rise." The number of new cases increased from 810 in 1929 to 1,775 in 1939. In a population of rather more than five millions, this represents a morbidity rate for 1939 of 31 per 100,000 , but inevitably many cases escape diagnosis.

In British East Africa, where there are few large cities and most of the natives live in scattered villages, tuberculosis, although a serious medical problem, has spread much less than in South Africa.

(c) West Africa.-In Nigeria, 1,012 cases of tuberculosis of all forms were notified during 1940, and of these 291 ended fatally ("Report on Medical Services of Nigeria," 1940). It is difficult to deduce morbidity or mortality rates from this, since the 22 million natives of Nigeria are scattered over such an enormous area. An indication of a rise in the incidence of tuberculosis is obtained from the number of certified deaths from tuberculosis in Lagos, which have increased from an average of 71 per annum for the years 1919-23 ("Medical and Sanitary Report for Nigeria," 1923) to 196 in 1938 ("Report on Medical Services of Nigeria," 1940). From available evidence (Calmette, 1921 ; Dumas, 1919), tuberculosis, although prevalent in towns with large European populations, is by no means so formidable a problem as it is in South or East Africa. 


\section{Pathology}

Borrel (1920), in a study of 500 post-mortem examinations on French Senegalese troops who died of tuberculosis in France during the 1914-18 War, classified the lesions as follows:

\begin{tabular}{lllllllc} 
& \multicolumn{1}{c}{ per cent } & \multicolumn{3}{c}{ per cent } \\
Pneumonic ... $\ldots$ & $\ldots$ & 30 & Serous ... & $\ldots$ & $\ldots$ & $\ldots$ & 10 \\
Disseminated caseous & $\ldots$ & 20 & Glandular & $\ldots$ & $\ldots$ & $\ldots$ & 5 \\
Haematogenous miliary & $\ldots$ & 25 & Chronic “ European ” type & $\ldots$ & 5 \\
& & & Abdominal and osseous & $\ldots$ & 5
\end{tabular}

For the most part Borrel's patients deteriorated rapidly and died before the stage of cavitation had been reached.

In the "Report on Tuberculosis in South African Natives" (1932), Pirie and Mavrogordato classified their post-mortem findings in 241 cases of tuberculosis in mine labourers as follows:

$\begin{array}{lllllll}\text { Acute caseating tuberculosis } & \ldots & \ldots & \ldots & \ldots & \ldots & 70\end{array}$

$\begin{array}{lllll}\text { Acute caseating tuberculosis with cavitation } & \ldots & \ldots & \ldots & 102\end{array}$

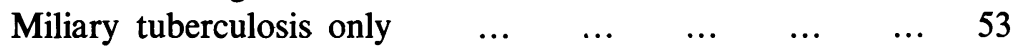

$\begin{array}{lllllll}\text { No tuberculosis in lungs } & \ldots & \ldots & \ldots & \ldots & \ldots & 16\end{array}$

241

This is a selected series, since men who were fit enough were repatriated; hence, it is not surprising that only acute forms of pulmonary disease were found.

Autopsy Findings in the Present Series. - Fifty-one of the 416 patients died in hospital during the year, and post-mortem examinations were performed on 50 .

Two deaths occurred as a result of miliary tuberculosis. One patient was admitted with a tuberculous ulcer of the base of the neck posteriorly, measuring $2 \frac{1}{2}$ in. in diameter, which had first appeared a year previously and had gradually increased in size, and bilateral cervical adenitis. Whilst in hospital he suddenly developed acute miliary tuberculosis and died. Post-mortem examination revealed masses of caseous glands in the neck, mediastinum, and abdomen, advanced miliary tuberculosis of both lungs, and very extensive tuberculous peritonitis. The liver, spleen, and kidneys showed no macroscopic evidence of tuberculosis. The other patient was admitted to hospital with a history of breathlessness for one week; a radiograph showed a large pleural effusion on the right side. After two months he suddenly became ill with high fever and died a month later. Post mortem examination showed a large clear sterile pleural effusion and miliary tubercles in the lungs, liver, spleen, and kidneys. There were a few caseous mediastinal glands.

One death was due to tuberculous pleurisy and peritonitis with terminal miliary dissemination. The patient was admitted with a large right pleural 
effusion, moderately enlarged liver, and ascites. He subsequently developed effusions in his pericardium and left pleural cavity, and died three months later. Autopsy revealed a grossly thickened pleura on the right side; over the diaphragm it was two inches thick in places and contained masses of caseous material, the largest of which had ulcerated through into the right lower lobe. Tubercles were scattered throughout both lung fields. The peritoneum was grossly studded with tubercles, but none were visible in the liver, spleen, or kidneys. Caseation was present in the abdominal glands.

The remaining 47 fatal cases showed parenchymal disease with a strikingly similar basic pathology. In the great majority there was evidence of acute caseating tuberculosis starting in one or both upper lobes and spreading throughout the lungs, the degree of cavity formation depending upon how soon the condition proved fatal. Extensive caseating parenchymal lesions were present in all cases ; both lungs were involved in 46. Cavitation had developed in all but one of the cases, and was bilateral in 26. A large cavity, or system of cavities, was found in an upper lobe in no fewer than 38. For the most part, the cavities had ragged walls, and contained large quantities of pus, caseous material, and debris. Since the average length of time from the onset of symptoms to death was 5.4 months in the patients who died in hospital during the year, the rapidity with which gross cavitation occurred is evident. Extensive pleural adhesions were an almost constant finding, and pleural effusions, of at least half a pint, were present in 15 of the cases. The heart was typically small and pale, with an excess of pericardial fluid ; pleura-pericardial adhesions were common.

The incidence of macroscopic evidence of glandular involvement in the 50 cases was as follows:

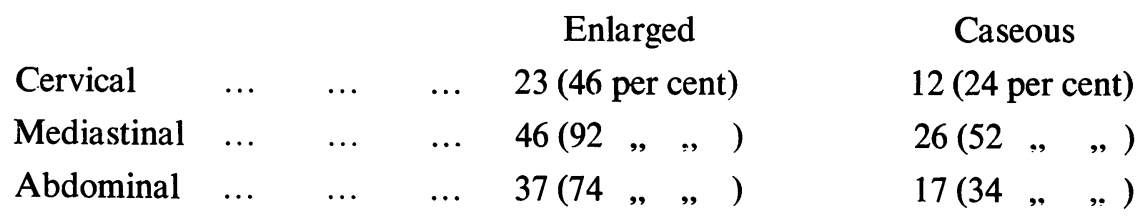

In the great majority, the enlargement was two to three times the normal size. Rarely, there were large masses of caseous glands containing pus. Glandular enlargement of some degree in either the cervical, mediastinal, or abdominal region was noted in 96 per cent of cases, and caseation was present in 66 per cent in at least one of these three regions. This incidence is far in excess of that found in Europeans of similar age ; it is characteristic of the disease in negroes, and is similar to the findings in both the mine labourers and Borrel's Senegalese troops.

Tuberculous involvement was evident to the naked eye in the liver in 6 per cent, the spleen in 20 per cent, and the kidneys in 8 per cent. One case showed massive areas of caseation in the liver and spleen. In the others, the lesions were 
slight and not sufficiently extensive to be regarded as a contributory cause of death.

Ulceration of the ileum was found in 50 per cent.

\section{Clinical Aspects}

Borrel (1920), describing his experiences with Senegalese troops in France during the 1914-18 War, had a unique opportunity of studying a large number of African natives who had had practically no previous contact with tuberculosis and were suddenly placed in a highly infected community under adverse climatic conditions. On arrival in France, only 4-5 per cent of the troops gave a positive von Pirquet reaction. He divided the clinical course into two phases: a glandular afebrile phase, lasting one to three months, merging into an acute phase, leading to death within two months.

Evidently Borrel encountered a very acute form of tuberculosis, with very little resistance, natural or acquired.

In the present series the course was generally not so acute ; in cases presenting with glandular involvement transition into pneumonic and miliary forms was rarely seen, and very few patients died within two months of the onset of acute lesions. The 416 cases fell into four easily distinguishable groups-glandular, parenchymal, serous and miliary-and may be classified as follows:

per cent

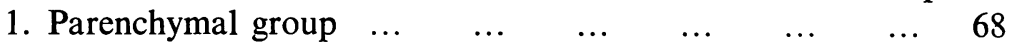

$\begin{array}{lllll}\text { (a) } \text { acute } \quad \ldots & \ldots & \ldots & 51 \text { per cent }\end{array}$

(b) subacute $\begin{array}{lllll} & \ldots & \ldots & \ldots & 12,\end{array}$

(c) chronic $\quad \ldots \quad \ldots \quad \ldots \quad 5$, ,

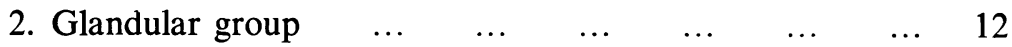

$\begin{array}{llllllll}\text { 3. Serous group } & \ldots & \ldots & \ldots & \ldots & \ldots & \ldots & 19\end{array}$

$\begin{array}{lllllllll}\text { 4. } \text { Miliary } & \ldots & \ldots & \ldots & \ldots & \ldots & \ldots & \ldots & 1\end{array}$

\section{Parenchymal Group}

(a) Acute cases numbered 212, or half the total number of admissions during the year. They represent a type of disease infrequently seen in European adults. The lesions were predominantly exudative and spread rapidly, with little respect for interlobar boundaries; cavitation and bronchogenic dissemination were common and occurred in the great majority sooner or later. In the most acute cases death occurred in one to three months from the onset of symptoms, at the end of a hectic course, with prostration, high fever, and emaciation. In those who survived for more than three months, cavitation was usually marked, and often extreme. Owing to the short period of observation (average two months for the whole series) no case was seen which ultimately became quiescent. 
The predominant lesions, as seen in the first available radiographs, were as follows :

\begin{tabular}{llllllr} 
Pneumonic consolidation of an upper lobe & $\ldots$ & $\ldots$ & $\ldots$ & 91 \\
Infiltration of an upper zone $\ldots$ & $\ldots$ & $\ldots$ & $\ldots$ & $\ldots$ & 80 \\
Infiltration of both upper zones & $\ldots$ & $\ldots$ & $\ldots$ & $\ldots$ & 21 \\
Infiltration of middle or lower zones & $\ldots$ & $\ldots$ & $\ldots$ & $\ldots$ & 17 \\
Infiltration of all zones $\ldots$ & $\ldots$ & $\ldots$ & $\ldots$ & $\ldots$ & $\ldots$ & 3 \\
\hline
\end{tabular}

Under " infiltration" are included all the cases which did not start with large homogeneous areas of pneumonic consolidation; they showed mainly scattered, discrete lesions in the early stages, which later tended to coalesce irregularly.

Pneumonic consolidation, occupying a considerable part or the whole of the upper lobe, was present in 91 (22 per cent of the whole series), and probably had been the initial pulmonary lesion in others which had reached the stage of cavitation by the time the first radiograph was taken. Cavities were seen radiologically in 180 of the patients prior to death or repatriation, and nearly all the patients who survived for six months from the onset of symptoms showed an upper lobe either completely excavated or replaced by a network of cavities. In cases in which the initial lesions were predominantly infiltrative, the rate of local spread, cavitation, and bronchogenic dissemination was almost as rapid as in the pneumonic variety. When the disease started in the middle or lower zones, the clinical course did not differ from that seen in cases with similar lesions starting in the upper zone.

The prognosis for this sub-group of cases is difficult to assess. Many of the very acute cases were too ill to be moved to our hospital and died elsewhere. All that can be stated is that almost a quarter of those admitted were unfit to stand a sea voyage and were retained in hospital until they died ; judging by the appearances of the remainder, it is most unlikely that even half of them would live for a year from the time of evacuation. No fewer than 48 of the 51 patients dying in hospital during the year fell into this sub-group.

The following two cases are instances of pneumonic consolidation of an upper lobe, with cavitation and bronchogenic dissemination.

Case 1. (Aged 30, Tanganyika.) Admitted to hospital on June 6, 1945, complaining of lassitude and sweating for three days. There were signs of consolidation in the right upper zone. Sputum T.B. positive. Radiograph on June 7 showed pneumonic consolidation of the right upper lobe with a large apical cavity, infiltration of the right middle and lower zones, and an acute spread to the left mid-zone. During two months' observation his general condition and fever $\left(99^{\circ}-101^{\circ}\right)$ remained unchanged, and weight remained constant, blood sedimentation rate fell from $90 \mathrm{~mm}$. to $80 \mathrm{~mm}$. at 1 hour (Westergren), and his sputum continued to be T.B. positive. Radiograph on July 7 showed slight spread in all zones (Fig. 1).

Case 2. (Aged 35, Bechuana.) Admitted to hospital on June 2, 1945, with one week's history of cough and lassitude. He was febrile $\left(99^{\circ}-101^{\circ}\right)$ and had signs of consolidation in the right upper zone. Sputum T.B. positive. Radiograph on June 4 showed consolida- 
TUBERCULOSIS IN AFRICAN NATIVE TROOPS
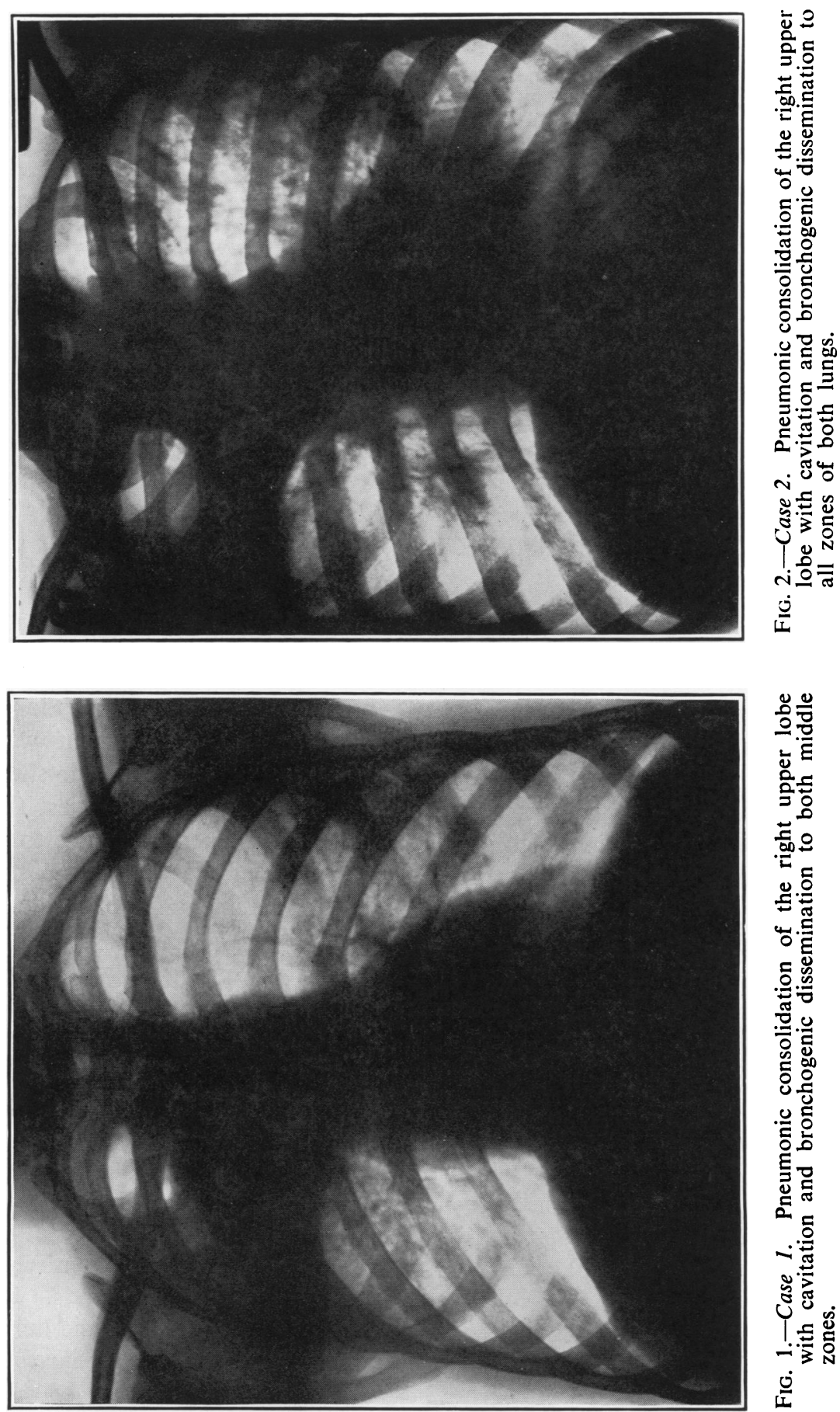
tion and cavitation of the right upper lobe with an early spread to the left mid-zone. During the next four months his general condition steadily deteriorated. He continued to be pyrexial and his B.S.R. rose from $60 \mathrm{~mm}$. to $94 \mathrm{~mm}$. (Westergren). He lost $5 \mathrm{lb}$. in weight. Radiograph on October 1 showed some retraction of the right upper lobe and a great increase in the size of the cavity; in addition, there was spread of the infiltration to all zones of both lungs with several small cavities (Fig. 2).

(b) Subacute cases, totalling 49, showed the type of disease usually seen in young adult Europeans. The initial lesion was in one or both upper zones in all but two, and 21 had proceeded to the stage of cavitation. Tubercle bacilli were found in the sputum of 29 at some stage of the disease. The immediate response to treatment, by rest in bed, was satisfactory in the majority, and, so far as could be seen, the ultimate prognosis was comparable with that in a similar group of Europeans.

(c) Chronic cases, 21 in all, showed little or no evidence of activity. All were afebrile, and the majority had normal blood sedimentation rates. Only seven showed tubercle bacilli in their sputum at any time. In the main, they had scattered infiltration in the upper zones, which was unilateral in 17 ; none showed radiological evidence of cavitation.

\section{Glandular Group}

This comprises 53 cases, in which the most prominent feature in the chest, radiologically, was the presence of enlarged mediastinal glands. In 18, the tuberculous activity appeared to be limited to the glands; in the others, parenchymal lesions were present, but the glandular enlargement was predominant. The degree of enlargement varied from "prominent hilar shadows" to large masses of glands occupying a considerable part of the chest (Fig. 3). There were five cases in which gross glandular enlargement gave rise to venous obstruction, causing distension of the veins of the neck. Of the 53 patients, there was radiological evidence of glandular enlargement on one side of the mediastinum in 26, and both sides in 27.

The clinical course and the severity of the constitutional upset varied strikingly with the type and extent of the parenchymal lesions. In cases in which the tuberculous activity appeared to be limited to the mediastinal glands there was usually little evidence of toxaemia. Once the disease became firmly established in the substance of the lung, however, it spread steadily and cavitation usually appeared sooner or later.

These "glandular" cases, which form so characteristic a feature of primitive tuberculosis, run a far less hectic course than the acute "parenchymal" varieties already described. The immediate prognosis is much better and no patient was unfit for repatriation by sea. The prognosis depends almost entirely upon whether the disease can be "contained" within the mediastinal glands. If it can there is every reason to anticipate a favourable outcome, but once the lungs have become seriously affected there is little hope of arresting the progress of the disease. 

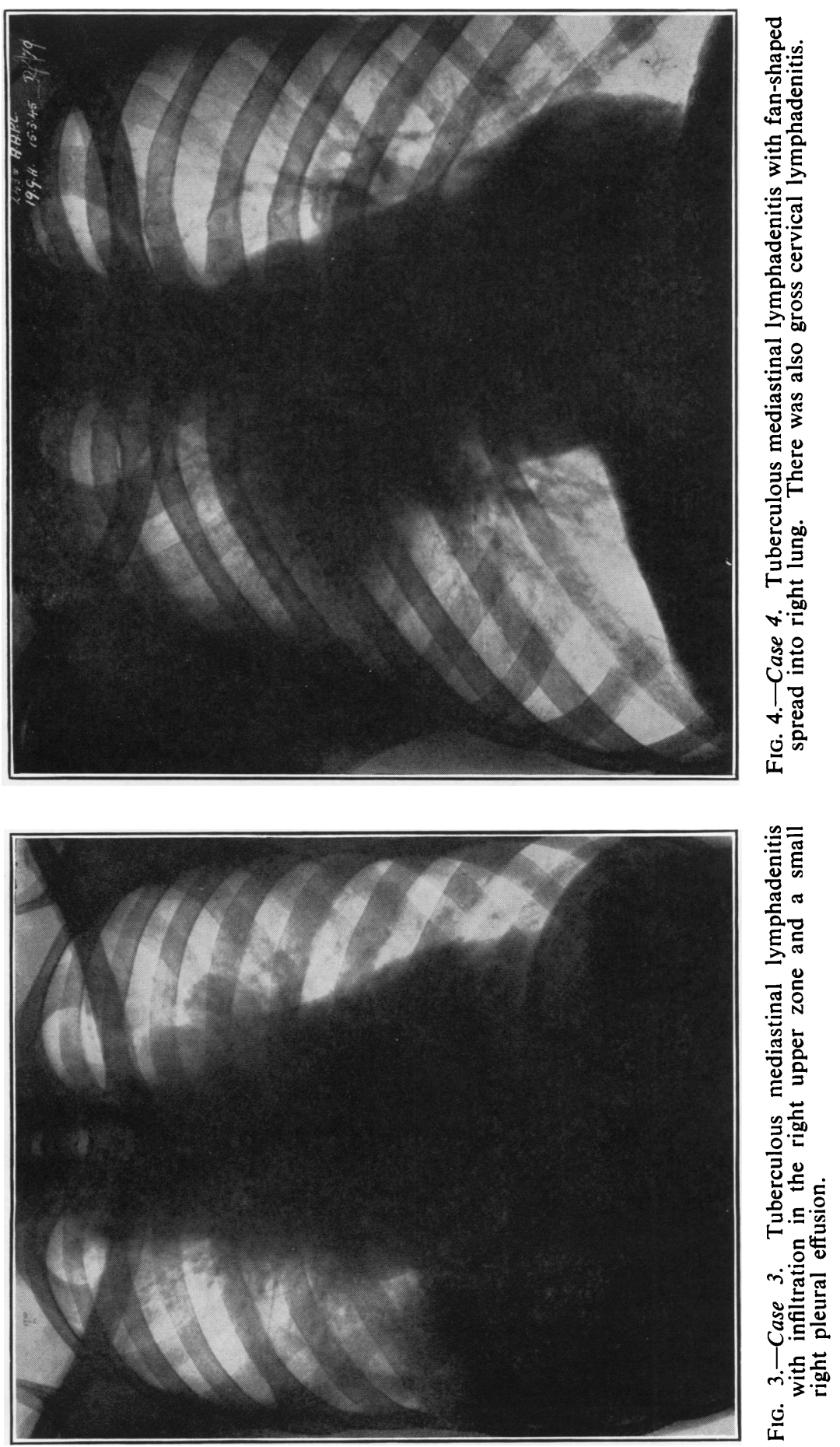
The following are three instances of "glandular" tuberculosis :

Case 3. (Aged 35, Bechuana.) Admitted to hospital on April 2, 1945, complaining of cough and breathlessness for three months. He was afebrile. There was slight stridor, but no evidence of engorgement of the neck veins, and no palpable enlargement of the superficial glands, liver, or spleen. Sputum T.B. negative. Radiograph on April 2 showed a very large mass of mediastinal glands, scattered infiltration in the right upper zone, and a pleural effusion on the right side. During two months' observation, no change either in his local or general condition was noted. He remained afebrile, gained $2 \mathrm{lb}$. in weight, B.S.R. fell from $76 \mathrm{~mm}$. to $40 \mathrm{~mm}$. (Westergren), and of five further sputum tests two showed tubercle bacilli. Radiograph on May 26 showed no change (Fig. 3).

The gross glandular enlargement in the mediastinum, compared with the small amount of parenchymal involvement, is striking. In cases such as this, with little parenchymal involvement, the constitutional upset was usually slight and fever absent.

Case 4. (Aged 30, Nigeria.) Admitted to hospital on March 13, 1945, with cold abscesses of both sides of the neck of one month's duration. His general condition was poor; one abscess had ulcerated through the skin above the right clavicle, and another, below the left ear, required aspiration. Typical tuberculous pus was obtained from both, but no tubercle bacilli were seen on direct smear. He was febrile $\left(99^{\circ}-100^{\circ}\right)$. Radiograph on March 15 showed a large mass extending out from the right hilum, to involve the right upper and mid-zones (Fig. 4). During four months' observation he steadily deteriorated, continuing to run a mild fever and losing $6 \mathrm{lb}$. in weight. His B.S.R. rose from $78 \mathrm{~mm}$. to $85 \mathrm{~mm}$. (Westergren). His sputum was always scanty and tubercle bacilli were demonstrated for the first time in July. Radiograph on June 26 showed spread of the consolidation to involve almost the whole of the right upper and mid-zones. No abnormality was seen on the left side.

Case 5. (Aged 28, Kenya.) Admitted to hospital with three cold abscesses, each about the size of a gold ball, over the 7th, 8th, and 9th ribs respectively on the left flank, which had gradually developed during the previous month. His general condition was good; he ran a mild evening pyrexia. Radiograph showed a very large mass of mediastinal glands and scattered infiltration throughout the left lung. Sputum T.B. negative. No change took place during three weeks' observation.

\section{Serous Group}

All the patients in this group, 78 in number, suffered from pleural effusion ; some had pericarditis, peritonitis, or minor degrees of parenchymal infiltration in addition. In general, uncomplicated pleural effusions did not differ from those seen in young adult Europeans; the amount of fluid tended, perhaps, to be greater, but the macroscopic and microscopic appearances were similar, and the response to rest in bed equally satisfactory. However, more than one serous cavity was involved in so high a proportion of cases that this must be regarded as a characteristic feature of the disease in African negroes; it occurred as follows:

4 bilateral pleural effusions

6 bilateral pleural effusions with ascites

2 unilateral pleural effusion with ascites

2 unilateral pleural effusion with pericardial effusion.

This marked tendency towards the development of polyserositis (18 per cent 
of the 78 cases) necessitates a close watch being kept on all the serous cavities throughout the course of the disease. As soon as more than one serous cavity becomes affected, the prognosis becomes considerably less favourable, as is seen from a summary of the more serious cases:

(1) Admitted with a moderate-sized right pleural effusion and minimal infiltration in the left upper zone; four months later the effusion occupied the whole of the right chest, the infiltration on the left had spread down to the mid-zone, and there was a moderately large left pleural effusion.

(2) Admitted with resolving right pleural effusion of 14 months' duration, scattered infiltration in the right upper zone, and a large recent left pleural effusion. The condition remained stationary during a month's observation.

(3) Admitted with a moderately large left pleural effusion and advanced peritonitis with ascites - stationary during 10 days' observation.

(4) Admitted with moderately large bilateral pleural effusions; during two months' observation the effusions became smaller, but ascites developed.

(5) Admitted with moderately large right pleural effusion and cervical adenitis; developed a left pleural effusion and peritonitis during six months' observation.

(6) Admitted with moderately advanced peritonitis, but no pulmonary or pleural lesion ; developed a large right pleural effusion and increase in the ascites during the subsequent four months.

(7) Admitted with fairly large bilateral pleural effusions and cervical adenitis; the effusion on the left side increased in size and ascites developed during the following three months.

(8) Admitted with a large right pleural effusion; developed a moderately large left pleural effusion and ascites, and died six months later.

\section{Miliary Group}

The majority of cases of miliary tuberculosis were unfit to be transferred from other hospitals in the Mediterranean area. Of the three cases observed in this series, two died in hospital (see section on Pathology) and the other showed miliary lesions throughout both lung fields with little constitutional upset, and was fit for repatriation by sea.

\section{Differences Between East, West, and South Africans}

The countries of origin of the 416 patients under review was as follows:

$\begin{array}{llrrrrrrr}\text { East Africans } & \ldots & \ldots & \ldots & \ldots & \ldots & \ldots & \ldots & 111 \\ \text { Uganda } & \ldots & \ldots & \ldots & \ldots & 35 & & & \\ \text { Kenya } & \ldots & \ldots & \ldots & \ldots & 32 & & & \\ \text { Tanganyika } & \ldots & \ldots & \ldots & \ldots & 44 & & & \\ \text { High Commissioned } & \ldots & \text { Territories } & \ldots & \ldots & \ldots & \ldots & 194 \\ \text { Basutoland } & \ldots & \ldots & \ldots & \ldots & 119 & & & \\ \text { Bechuanaland } & \ldots & \ldots & \ldots & 57 & & & \\ \text { Swaziland } & \ldots & \ldots & \ldots & \ldots & 18 & & & \\ \text { Cape Coloured } & \ldots & \ldots & \ldots & \ldots & \ldots & \ldots & \ldots & 77 \\ \text { West Africans } & \ldots & \ldots & \ldots & \ldots & \ldots & \ldots & \ldots & 32 \\ \text { Northern Rhodesians } & \ldots & \ldots & \ldots & \ldots & \ldots & \ldots & 2 \\ \end{array}$


Tentative estimates of morbidity, based on the number of troops serving in the Mediterranean area during the year, allowance being made for those patients unfit to be transferred to our hospital, give the following incidences:

$\begin{array}{lccccccc}\text { High Commissioned } & \text { Territories } & \ldots & \ldots & \ldots & \ldots & 6.6 \\ \text { East Africans } & \ldots & \ldots & \ldots & \ldots & \ldots & \ldots & 4.3 \\ \text { West Africans } & \ldots & \ldots & \ldots & \ldots & \ldots & \ldots & 2.5\end{array}$

No estimate is possible for the Cape Coloured.

Several factors are of importance in determining the high incidence in the High Commissioned Territories (H.C.T.) troops. Unlike the East and West Africans, they saw active service in North Africa and Italy. Their average age (35) was seven years greater than the others, and no less than 70 per cent of them had previously worked in the mines in South Africa. As civilian experience has shown, a high incidence of pulmonary tuberculosis is to be expected if natives over the age of 35 , who have previously worked in the mines, are employed in any capacity involving physical and mental strain.

A comparison between the incidence of the four main clinical types of disease -parenchymal, glandular, serous, and miliary-in the four main racial groups is seen in the following table (expressed as percentages of the total number in each racial group):

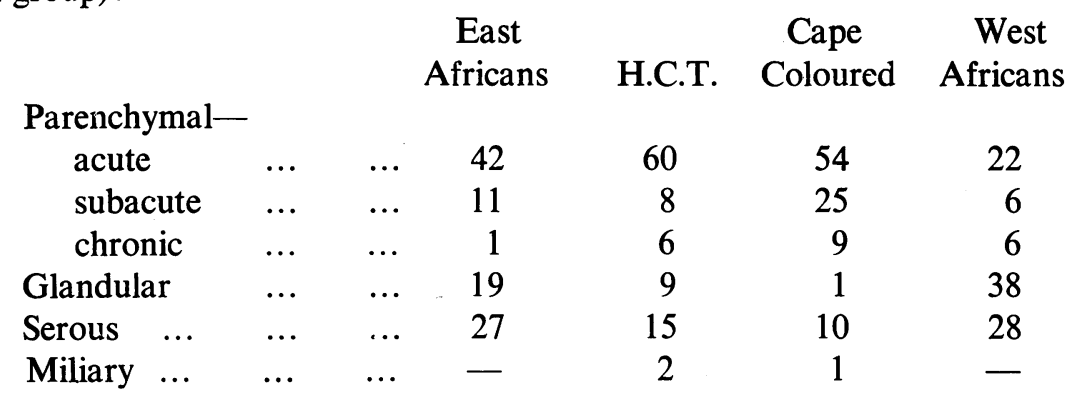

The high proportion of glandular and serous forms amongst the East and West Africans is the most striking feature, and indicates, at least so far as the glandular group is concerned, that these races develop a more "primitive" type of tuberculosis in early adult life than the South Africans. The tendency towards chronicity amongst the Cape Coloured is also notable and may be attributable to the mixture of European with native blood.

The percentages of patients from the various parts of Africa dying during their stay in the hospital are shown in the following table:

$\begin{array}{lllllc}\text { H.C.T. troops } & \ldots & \ldots & \ldots & \ldots & 19.5 \\ \text { Cape Coloured } & \ldots & \ldots & \ldots & \ldots & 9 \\ \text { East Africans } & \ldots & \ldots & \ldots & \ldots & 4.5 \\ \text { West Africans } & \ldots & \ldots & \ldots & \ldots & 3\end{array}$


The 51 patients who died in hospital during the year are merely those who were unfit to be repatriated by sea. However, the striking racial differences strongly suggest that the South African negroes develop a type of disease with a considerably higher early mortality than the East or West Africans, even though the higher incidence of glandular and serous lesions, seldom causing early death, partly accounts in the latter races for these differences.

\section{TREaTMENT}

Owing to the acute nature of the disease, 90 per cent of the patients were confined to bed throughout their stay in hospital.

The advisability of collapse therapy in negroes is debatable. The literature on African experience is very scanty, but the results of such treatment in American negroes have been very disappointing (Chadwick, Markoe and Thomas, 1933; Gaines and Keller, 1933 ; Brock, 1933 ; Cutler, Rodgers and Cippes, 1934 ; Fisher, 1937). In this series 14 artificial pneumothoraces (A.P.) had been induced at other hospitals prior to admission; none was induced in our hospital. Acute bronchogenic spreads or pleural effusions or both ensued in nearly every case, as can be seen from the following summaries:

(1) R.A.P. induced for acute pneumonic unilateral disease with cavities; abandoned three months later because the cavities were unaffected, consolidation increased on the right side and there was an acute spread to the left side. He died five months after the induction of the R.A.P. with extensive bilateral disease.

(2) L.A.P. induced for "early" infiltration in the upper zone; there were extensive apical adhesions, and a small cavity subsequently became evident in the upper zone. No other complications developed during four months' observation.

(3) L.A.P. induced for fairly extensive unilateral infiltration and cavitation; abandoned a month later on account of extensive apical and basal adhesions. Gross spread of the disease to all zones of the right lung during the following month.

(4) L.A.P. induced in the presence of fairly advanced disease in the left upper and mid-zones and in the right mid-zone. Eight months later, radiograph showed an unsatisfactory L.A.P. with extensive apical adhesions, widespread infiltration in all zones of both lungs, and a large cavity in the left mid-zone.

(5) R.A.P. induced for pneumonic consolidation of the right upper lobe and scattered infiltration in both mid-zones. During the next six months, a large tuberculous empyema developed on the right side and the infiltration spread to all zones of the left lung.

(6) R.A.P. induced for scattered infiltration in the upper zone; a good collapse was obtained, and no change was noted during the subsequent four months.

(7) R.A.P. induced for fairly extensive infiltration of the upper zone. There were extensive apical adhesions, and a large hydropneumothorax developed within a month.

(8) Bilateral A.P. induced for fairly extensive infiltration of both upper and mid-zones with cavitation in the left mid-zone. Radiograph two months later showed spread of infiltration in both lung fields, bilateral apical adhesions, and pleural effusions.

(9) L.A.P. induced for fairly extensive infiltration of the left upper and mid-zones with cavitation. There were extensive apical adhesions. During the next four months the infiltration and cavitation increased very considerably on the left side.

(10) L.A.P. induced for scattered infiltration in the left upper and mid-zones. Many apical adhesions were present, and a large pleural effusion developed within a month. 
(11) R.A.P. induced for extensive infiltration of the right upper and mid-zones with cavitation. Within four months a large hydropneumothorax developed, and infiltration spread to all zones of the left lung.

(12) L.A.P. induced for infiltration of all zones of the left lung, with cavitation in the upper zone. Radiograph three months later showed a satisfactory L.A.P., but the cavity in the upper zone had increased in size and there was extensive infiltration in all zones of the right lung.

(13) L.A.P. induced for extensive infiltration of the left upper and mid-zones, with a large cavity in the upper zone, and scattered infiltration of the right mid-zone. During the next six months a large pleural effusion developed on the left side and the infiltration spread to all zones of both lungs.

(14) R.A.P. induced for pneumonic consolidation of the right upper lobe and scattered infiltration in the right middle and lower zones. He died three months later with extensive bilateral disease.

These cases clearly indicate the futility of collapse therapy for acute or advanced lesions. It may be that really "early" cases might benefit from a pneumothorax which could be properly maintained for two to three years. These, however, are very few and far between, and their chances of controlled refills over a long period in their home countries, except in the large cities, are remote.

No case in this series presented lesions suitable for thoracoplasty or other major surgical measures of collapse therapy.

\section{Discussion}

In general, the clinical and pathological findings in this study closely resemble those in the mine labourers described in the "Report on Tuberculosis in South African Natives" (1932). This is due largely to a high incidence of previous contact with tuberculosis in both series.

Sixty-five per cent of the mine labourers were Mantoux-positive when first employed, and of those who subsequently developed tuberculosis, more than twothirds were initially Mantoux-positive, indicating that the majority suffered from the reinfection type of tuberculosis. Indeed, emphasis is placed in the Report upon the reactivation of pre-existing foci as a result of the added physical and mental strain of working in the mines. No large tuberculin surveys were undertaken among the coloured African troops in the Middle East, but Mantoux testing in their countries of origin, as has already been stated, has shown that a high proportion of the adult males have become infected.

In Borrel's series, probably the most primitive type of tuberculosis ever recorded in a group of adults, previous contact with tuberculosis was minimal. The patients exhibited mainly the immediate effects of primary infection, the mode of dissemination of the disease depending almost entirely upon the behaviour of recently infected mediastinal glands. The rapidly fatal clinical course described by Borrel was rarely seen in the present series. In our "glandular" group, a dramatic conversion to acute tuberculosis was uncommon and no death occurred within two months of the development of parenchymal 
lesions. On the other hand, post-mortem examinations frequently revealed acute forms of pulmonary tuberculosis in association with caseous mediastinal glands.

The following table correlates the type of pulmonary lesions found in the first available radiographs with the presence or absence of caseation in the mediastinal glands at autopsy in the 50 fatal cases of the present series.

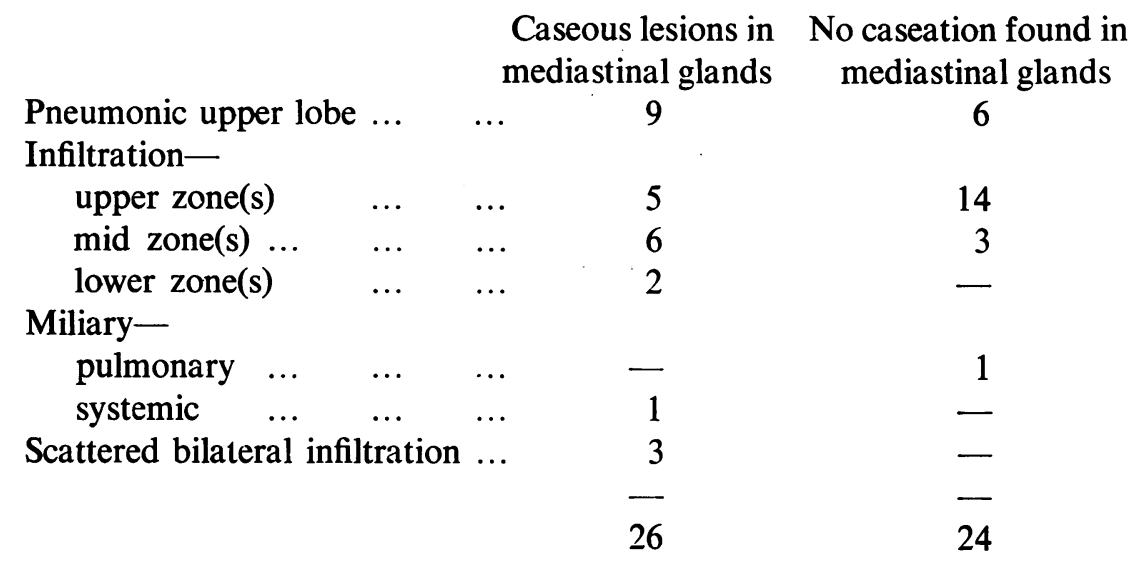

The table shows that caseous mediastinal glands were present in 26 of the 50 cases at post mortem. A similar incidence was found by Everett (1933) in adult American negroes; Borrel found caseous tracheo-bronchial glands in 80 per cent of his Senegalese. These high incidences denote a close relationship between the lesions of primary infection and the development of pulmonary tuberculosis in adult life in negroes. The very high incidence in Borrel's cases is in keeping with his observation that only 4-5 per cent showed a positive skin reaction to tuberculin on arrival in France, and emphasizes again the important part played by the effects of primary infection in his series. In our troops and the American negroes reported by Everett, both of whom had considerable previous contact with tuberculosis, caseous mediastinal glands had become a less prominent feature by the time of death, suggesting that the glandular component of primary infection had become inactive in a high proportion of cases.

How much importance should be placed upon the presence or absence of caseation in mediastinal glands in deciding whether lesions are of the primary or reinfection type is difficult to determine. Everett (1933), in a study of autopsy material in American negroes, states: "The occurrence of caseous tuberculosis in lymph nodes in the line of lymphatic drainage from a tuberculous focus in the lung has been accepted as evidence of first infection; 22 lesions with lymph node involvement found in 44 cases of pulmonary tuberculosis in adult negroes have been designated as the childhood type of disease." On the other hand, pulmonary lesions with enlarged mediastinal glands (the European "childhood" type) have been observed in adult negroes in association with old calcified primary lesions 
(Pinner and Kasper, 1932 ; Rich, 1944), suggesting that the mediastinal glands in negroes may react to a reinfection in the same way as those of white children react to a primary infection. However, in view of the considerable enlargement of the mediastinal glands which characteristically occurs in negroes following primary infection, there is likely to be a long latent interval before the glandular lesions become finally arrested or healed. Fresh lesions arising in the lungs during this latent period are likely to be of the type associated with fully developed allergy (that is, the European "adult" type), although the mediastinal glands remain caseous.

In this series many instances of the "reinfection" type of lesion, as found in European adults, were seen ; the great majority of the cases which, radiologically, began with infiltration of one or both upper zones and nearly half the pneumonic cases had no caseation in the mediastinal glands at autopsy. There remains, however, a large group in which early radiographs showed infiltrating or pneumonic lesions associated with caseating mediastinal glands; in these the parenchymal lesions presumably arose before the glandular lesions of primary infection had become arrested. They were not fulminating cases, as described by Borrel, and it is likely that many developed fresh pulmonary lesions while the glandular lesions of primary infection were still showing active caseous changes.

\section{SUMMARY}

The clinical features of pulmonary tuberculosis in 416 African native troops in whom the disease was diagnosed whilst on active service in the Mediterranean theatre of war are described. They were studied at a hospital in Egypt to which all such cases were sent to await repatriation.

The cases fell into four easily recognized clinical groups: parenchymal, glandular, serous, and miliary.

The parenchymal group was the largest, comprising 282 cases; of these, 212 showed rapidly spreading acute lesions of a type rarely seen in European adults and the remaining 70 had subacute and chronic lesions of the European type.

The glandular group of 53 cases exhibited varying degrees of mediastinal glandular enlargement ; the gross enlargement seen in many of them is a characteristic of the disease in adult negroes.

The serous group, 78 in number, comprised 19 per cent of the total number of cases ; 14 of these showed involvement of more than one serous cavity.

The miliary group was small, consisting of only three cases, probably because such cases were rarely fit for transfer.

The findings are compared with those in previously reported series of cases of pulmonary tuberculosis in African negroes. 


\section{REFERENCES}

Allan, P. (1932). No. 30, Vol. 5, Pubs., S. Afr. Inst. med. Res.

Annual Report of the Medical Department, Tanganyika (1935, 1936, and 1940).

Borrel, A. (1920). Ann. Inst. Pasteur, 34, 105.

Brock, B. L. (1933). Am. Rev. Tuberc., 28, 767

Calmette, A. (1921). Rev. Hyg. et de Police Sanitaire, 43, 653.

Chadwick, H. D. Markoe, R. C. L., and Thomas, J. T. (1933). Am. Rev. Tuberc., $28,759$.

Cummins, S. L. (1939). Primitive Tuberculosis, London.

Cutler, J. W., Rodgers, W. H., and Cippes, I. B. (1943). Am. Rev. Tuberc., 30, 80.

Dormer, B. A., Friedlander, J., and Wiles, F. J. (1943). Proc. Transv. Mine med. Offrs. Ass., 23, 257.

Dumas, A. (1919). Lyon Med., 128, 180.

Everett, F. R. (1933). Am. Rev. Tuberc., $27,411$.

Fisher, L. (1937). Am. Rev. Tuberc., 35, 62.

Gaines, A. R., and Keller, P. E. (1933). Am. Rev. Tuberc., 28, 779

Gregory, A. J. (1896). Annual Report of the Medical Officer of Health for Cape Colony, Capetown.

Israel, H. L., and Payne, H. M. (1940). Am. Rev. Tuberc., 41, 188.

Lichtenstein, H. (1803). Travels in South Africa (quoted by S. L. Cummins).

Livingstone, D. (1857). Missionary Travels and Researches in South Africa (quoted by S. L. Cummins).

Macvicar, N. (1908). S. Afr. Med. Rec., 6, 161, 181, 197, 213, and 229.

Medical and Sanitary Report for Nigeria (1923).

Opie, E. L. (1924). Am. Rev. Tuberc., 10, 265.

Opie, E. L. (1930). Am. Rev. Tuberc., 22, 603.

Pinner, M., and Kasper, J. A. (1932). Am. Rev. Tuberc., 26, 463.

Report on Medical Services for Nigeria (1940).

Rich, A. R. (1944). The Pathogenesis of Tuberculosis, Springfield, Illinois.

Smith, Elliott (1902). Brit. Med. J., 2, 1532.

Tuberculosis in South African Natives with special reference to the disease amongst Mine Labourers on the Witwatersrand (1932). Publication of the South African Institute of Medical Research, No. XXX (Vol. V).

Van den Branden, F., Fornara, L., and Staub, A. (1926). Ann. Soc. Belge. Med. Trop., 6, 235.

Wilcocks, C. (1932). E. Afr. Med. J., 9, 88. 